\title{
Translating Methods of Shakespeare in China
}

\author{
Yanna Sun \\ Dresden University of Technology \\ 7 Gecun Road, Jindu Dasha 908 \\ Nanning 530022, China \\ E-mail: sunyanna@yahoo.com.cn
}

\begin{abstract}
Shakespeare was not known to the Chinese until Lin Zexu's (1785-1850) translation of Hugh Murray's (1789-1845) Cyclopedia of Geography (1836). Afterwards Shakespeare in China saw many complicated changes, from being regarded as a story-teller to being fully received as a seasoned playwright and poet, and his plays were rendered into the Chinese language and performed on the Chinese stage. But first and foremost is the question of how to translate Shakespeare well, for translation is primarily important for those readers who have no knowledge at all of the English language.
\end{abstract}

Keywords: Chinese methods of rendering Shakespeare, Literal translation, Free translation

\section{Introduction}

Since the first real beginning of rendering a Shakespearean play into modern vernacular Chinese by Tian Han (1898-1968) with his Hamlet in the year 1921, many Chinese scholars have attempted to translate Shakespeare and his works. After the founding of the People's Republic of China in particular, apart from the ten-year Cultural Revolution between 1967 and 1977, Shakespearean translations along with performances and literary criticism continued to flourish. As far as Hamlet is concerned, Lu Gusun estimated that in post-1949 China "at least five translations have been added to the pre-1949 three, two of these five being attempts at a poetic rendering, and more than fifty monographs have been published." (Lu, 1983, p.55).

Generally speaking, there are two methods of translating: one is literal translation and the other is free translation. Literal translation requires the translator to keep loyal to the original work not only in content but also in style, while free translation emphasizes the importance of the target language. In terms of Chinese translation theory, Yan $\mathrm{Fu}$ (1853-1921) is said to be the first to put forward his three-character criteria. The Chinese have debated its practicability for almost a century; nevertheless this translation standard has been followed by many later translators in their renditions, consciously or unconsciously:

Translating is difficult in three aspects, namely, xin (faithfulness), $d a$ (readability), and ya (refinement). To aspire to perfection in faithfulness is rather difficult. However, to make the translation faithful without being readable is equal to having no translation at all. Hence the relative importance of readability [...] [B]esides xin (faithfulness) and $d a$ (readability), one should also pay attention to $y a$ (refinement). This is not only to let the text reach a wider audience; as a matter of fact, the discourse is so profound and full of nuances of meaning, it can only be made readable with ease by using the lexicons and grammar of the pre-Han period of two millennia ago; whereas it is difficult to use the current vulgar tongue to produce a refined version. (Fan, 1999, np).

Explained from the perspective of Chinese translation theory, literal and free translation are very different from each other with literal translation staying true to the author and the source language - xin (faithfulness) - while free translation leans towards the reader and the target language - $d a$ (readability). In other words, the choice of free and literal translation is decided by the respective goal. When the translator wants to simply introduce a foreign work, some stories and plots from the text for instance, to the ordinary reader, free translation is not a bad option to help the target reader understand the original well, because in this situation the content of the original is much more important than its style. The translating work here adheres to the opinion of similarity in spirit (shen si). By contrast, when the goal of rendering is to illustrate a foreign author, a well-known writer in particular, the original content and writing style including language, structure, rhetorical figures of speech and imagery both play a key role in translating, and therefore the method of literal translation is better, or the best, to preserve the original spirit. Only in this way can both the original works and the original writer be thoroughly appreciated by the Chinese reader, which is called similarity in spirit and form (shen xing jie si).

\section{Literal Translation in Rendering Shakespeare}

Bian Zhilin (1910-2000) is a representative in adopted literal translation in rendering Shakespeare. He translated the 
original into the Chinese language according to his principle of yibu yiqu - the translator should render the original by imitating the author at every step from the number of lines, rhyme, to feet.

Bian's translation of Hamlet was published under the title The Tragedy of Hamlet, Prince of Denmark in 1956 by the Beijing Writer Press. When rendering the play into Chinese, Bian preserved the original mode by "following the distribution of verse and prose in the old version and keeping every variation in the verse" (Zhou, 1981, p.217), as he wrote in his "Illustration to the Translation": "The original prose was translated in vernacular Chinese prose and blank verse was in unrhymed poetic form with five-dun [dun literally means a group of words] within a line. When there is rhyme in the original, correspondingly the translation is in verse as well." (Zhou, 1981, p.26).

To illustrate how Bian exercised literal translation in rendering the English playwright and poet, let's take Hamlet's soliloquy in Act III Scene I for example.

To be, $\quad \mid$ or not $\mid$ to be --- $\mid$ that is $\mid$ the quesiton:

huo xia qu | hai shi | bu huo: | zhe shi | wen ti.

$[t i]$

Whether | 'tis nob | ler in | the mind | to suffer

yao zuo dao | gao gui, | jiu jing gai | ren qi | ten sheng [sheng]

The slings | or arrows | of out | rageous | fortune

lai rong shou | kuang bao de | ming yun | shi shi | jiao gong ne, [ne]

Or to $\quad \mid$ take arms $\mid$ against $\mid$ a sea $\quad$ of troubles

hai shi gai $\mid$ ting shen $\mid$ fan kang $\mid$ wu bian de $\mid$ ku nao, [nao]

And by opposing | end them.

sao ta ge | gan jing?

[jing]

(Hamlet, 3.1.56-60) (Shakespeare, 1992, pp.56-60)

This soliloquy is in blank verse - unrhymed iambic pentameter; that is to say, Shakespeare adopted ten syllables in a line and then these ten syllables were divided into five pairs called iambic feet. Generally speaking, the foot consists of two syllables with the stress on the second one. At the same time, the lines are unrhymed. Compared to the so-called syllable and foot in the English language system, there is no such equivalent in the Chinese language. Accordingly, Bian Zhilin tried to create his own dun, although the idea of adopting five-dun in accordance with Shakespeare's five pairs of foot was put forward by Sun Dayu. (Sun, 1996, p.82).

Like Shakespeare's five pairs of iambic feet within a line, Bian adopted five dun - five groups in each two or three Chinese characters are put together - in his translation and meanwhile gave no rhyme between lines (see the Chinese pinyin in the square bracket). In the meantime he closely followed Shakespeare in the number of lines and even the order of them. Notwithstanding, to avoid inaccuracy resulting from blind faithfulness to the original Europeanized structures and expressions, Bian rearranged these two sentences from "For in that sleep of death what dreams may come / When we have shuffled off this mortal coil " into "Once we get rid of the mortal life / What we will dream of in the sleep of death".

Bian Zhilin's attempt has been accepted by the circle of Shakespearean studies and his version is regarded as one of the best Chinese translations of Shakespeare's Hamlet. (Meng, 1994, p.113). In theory, all that Bian Zhilin had done was to authenticate his principle of "seeking for similarity in spirit through preserving the original form" (cunxing qiushen).

\section{Free Translation in Rendering Shakespeare}

From his translation experience in introducing Western philosophical works to modern China, Yan Fu suggested that the translator "grasp the global spirit of the discourse, let the idea become part of your mind and then let the writing brush take care of itself. When it comes to an abstruse text, which cannot be understood all by itself, try to paraphrase it by adding explanatory remarks either afore or aft, to bring out its meaning." (Fan, 1999, np). In practice, the method of free translation is relatively popular in rendering Shakespeare into the Chinese language.

Zhu Shenghao (1912-1944) talked about his experience in his "Foreword" for the edition of The Complete Theatrical Works of William Shakespeare: "I will try to retain the spirit of the original as far as I possibly can; if this cannot be achieved, I will at least try to convey the intentions of the original, using fluent, plain Chinese; as to word-for-word 'hard' translations, I dare not venture to go along with.” (Fan, 1999, np).

To make a clear contrast with Bian Zhilin's literal translation, Zhu's version of Hamlet's soliloquy in Act III Scene I is also cited as example, which can be literally rendered back into Englsih in the following way:

To live or to destroy, this is a question that is worth considering. Which behaviour is much nobler: to speechlessly suffer the outrageous slings and arrows of fortune or to bravely rebel against endless troubles in the world and end them 
through struggle? (My translation of Zhu's version).

Comparing this with Shakespeare's blank verse and Bian Zhilin's literal translation in verse form, first of all, Zhu Shenghao did not arrange his version in lines; secondly, he added his explanatory remarks to the original text, such as the underlined words in the following sentences: "this is a question that is worth considering" and "Which behaviour is much nobler: to speechlessly suffer the outrageous slings and arrows of fortune or to bravely rebel against endless troubles in the world and end them through struggles?"; thirdly, Zhu reconstructed his sentences according to the Chinese syntax, for instance, "If our heartache and other numberless shocks that our flesh body cannot escape can disappear from now in such a sleep, that is what we most welcome", comparing with the original: "and by a sleep to say we end | The heart-ache and the thousand natural shocks | That flesh is heir to: "tis a consummation | Devoutly to be wish'd." (Hamlet, 3.1.61-4).

Though his translation of Shakespeare is not without errors, Zhu Shenghao's free translation is relatively faithful to the English text in similarity of spirit and is regarded as a good example of rendering Shakespeare:

Wherever the syntax of a sentence in the original text has been found to clash with the grammar of Chinese, I would always mull it over for hours and days until I came up with a version which was totally different in construction from the original, so much so that the intended message of the author had been brought to the foreground without being blurred by obscure Chinese. (Fan, 1999, np).

In conclusion, as far as translation ways of literal and free methods are concerned in practice, neither of them is completely wrong, as Lin Yutang distinguished between them as follows:

"Translation by word" could be used where the translation was deemed correct from the context; and "translation by sentence" had to be used where "translation by word" could not render the "global meaning" of the sentence. The global meaning of a sentence could not be derived [from] a simple summation of the meanings of each and every individual words making up that sentence. It could only be derived after grasping the global idea of the sentence. If the translation happened to be a word-for-word match of the original sentence, so much the better. Otherwise, the meaning of certain individual words had to be ignored in order to catch the global meaning of the sentence. (Fan, 1999, np).

So are Shakespearean translations in China.

\section{References}

Fan, Shouyi. (1999). Highlights of Translation Studies in China Since the Mid-Nineteenth Century. Meta XLIV1, np.

Lu, Gusun. (1983). Hamlet Across Space and Time. Shakespeare Survey 36, 53-56.

Meng, Xianqiang. (1994). Shakespeare in China: A Brief History. Changchun: Northeast Normal University Press.

Shakespeare, William. (1992). Hamlet. Repr. Ed. Harold Jenkins. London: Routledge.

Sun, Zhili. (1996). 1949-1966: On Translations of British and American Literatures of the PRC. Nanjing: Yilin Press.

Zhou, Zhaoxiang. (1981). Studies on Chinese Translations of Hamlet. Hong Kong: Chinese University Press. 